\title{
Actors and intentions in the development process of a mobile phone platform for self- management of hypertension
}

Agneta Ranerup and Inger Hallberg

\author{
Linköping University Post Print
}

\section{Tweet}

N.B.: When citing this work, cite the original article.

This is an electronic version of an article published in:

Agneta Ranerup and Inger Hallberg, Actors and intentions in the development process of a mobile phone platform for self-management of hypertension, 2015, Informatics for Health and Social Care, (40), 4, 299-318.

Informatics for Health and Social Care is available online at informaworldTM:

http://dx.doi.org/10.3109/17538157.2014.924948

Copyright: Taylor \& Francis: STM, Behavioural Science and Public Health Titles

http://www.tandf.co.uk/journals/default.asp

Postprint available at: Linköping University Electronic Press

http://urn.kb.se/resolve?urn=urn:nbn:se:liu:diva-121490 


\section{Actors and intentions in the development process of a mobile phone platform for self-management of hypertension}

Agneta Ranerup ${ }^{1,3 *}$, Inger Hallberg ${ }^{2,3}$

${ }^{1}$ Department of Applied Information Technology, University of Gothenburg, SE-412 96,

Gothenburg, Sweden

${ }^{2}$ Institute of Health and Care Sciences, Sahlgrenska Academy, University of Gothenburg, Box

457, SE-40530, Gothenburg, Sweden

${ }^{3}$ Centre for Person-centred Care (GPCC), Sahlgrenska Academy, University of Gothenburg, Box 457, SE-40530, Gothenburg, Sweden.

Running title: Development of a mobile phone platform

Keywords: Cellular phone, development process, hypertension, participatory design, selfmanagement

*Corresponding author

Email addresses:

AR: agneta.ranerup@ait.gu.se

IH: inger.hallberg@gu.se 


\section{Abstract}

\section{Aim}

The aim of this study was to enhance the knowledge regarding actors and intentions in the development process of a mobile phone platform for self-management of hypertension.

\section{Methods}

Our research approach was a 14-month longitudinal "real-time ethnography" method of description and analysis. Data were collected through focus groups with patients and providers, patient interviews, and design meetings with researchers and experts. The analysis was informed by the concepts of actors and inscriptions in Actor-Network Theory (ANT).

\section{Results}

Our study showed that laypersons, scientific actors, as well as technology itself, might influence development processes of support for self-management of hypertension. The intentions were inscribed into the technology design as well as the models of learning and treatment.

\section{Conclusions}

This study highlighted important aspects of how actors and intentions feature in the development of the mobile phone platform to support self-management of hypertension. The study indicated the multifacetedness of the participating actors, including the prominent role of technology. The concrete results of such processes included questions in the self-report system, learning and treatment models. 


\section{Introduction}

Mobile phone platforms are becoming an important method for patient monitoring in cases of chronic disease to improve and facilitate communication between providers and patients $[1,2]$. Although mobile phone platforms are used in a wide variety of settings, there are few studies that focus on the development process of the mobile phone platforms for disease management and health monitoring. The development can be seen as a way of inscribing the intentions of involved actors (laypersons, researchers and others) into a technology in order to provide support involving lay and scientific knowledge [3, 4]. From a global perspective, hypertension was the largest risk factor for cardiovascular disease [5] and mortality [6] in 2010. The case studied here was a development process of a mobile phone platform to support the selfmanagement of hypertension. The research approach was a longitudinal "real-time ethnography" method of description and analysis focusing on the appearing actors and intentions in this kind of process.

\subsection{Related studies}

\subsubsection{Mobile phone platforms in chronic illness}

Previous studies have shown that mobile phones and text messaging can be effectively used to improve health outcomes and the process of care [7-11]. Mobile phone platforms have been developed for use in the management of cancer and asthma as well as in the care of older people $[1,2]$. Chronic diseases such as asthma and diabetes, as well as smoking cessation [9], which require ongoing support and advice, benefited the most from these kinds of interventions [12].

More often than not, as in the case of a mobile phone platform to control obesity, the research focus is on the result or design only in a technical sense, rather than the development process [13]. Alternatively, the focus is on a rather distant account of the phases of the development process [14]. Regarding the monitoring of patients with hypertension, Logan et al. [15] offer a somewhat deeper description of the design principles and technical architecture as well as the quantitative outcome of a pilot study. Alternatively, Logan [16] pursued a 
principal discussion of mobile phone platforms in hypertensive care as part of inventing new technologies and forms of organizing care. However, a more in-depth description of actors and intentions in the development process of mobile phone platforms in general, and for hypertension in particular, is absent.

\subsubsection{The development of decision support for patients}

A broader theme serving to contextualize this study is research on processes during which technological decision support for patients is developed. Concerning the organizational aspects of development processes, Elwyn et al. [17] and Ekberg et al. [18] proposed ideal models of activities. Berry et al. [19] and Berg et al. [20] described development processes of Web-based decision support, providing an overview of phases. Pasternack et al. [21] described "the process and the challenges" when developing decision support, noting the risk of lack of feedback from patients as well as the need for careful thinking in selecting what to include in the design. Lehoux et al. [22] studied three cases of the development of what was characterized as medical technology, offering an ex post facto overview of the participating actors and their responsibilities, motivations and interactive use of expertise.

Regarding those who participate in the development processes, often discussed using the concept of Participatory Design (PD), this can be explored in several ways [23]. There are sometimes explicit forms of participation by clinicians [17, 18, 24]. Studies might also distinguish between providers or actors in possession of medical knowledge and others. Shah et al. [25] discussed this in terms of benefits of and barriers to patient participation, whereas Torsi et al. [26] discussed patients' experiences and how they can be incorporated into design. The issue of participation thus includes actors with both medical or scientific knowledge and lay knowledge [3, 4]. In contrast, there is a lack of "real-time ethnography" studies of development processes [27] with a focus on those who participate, and their intentions and forms of knowledge [3, 4]. 
In sum, what really happens in such processes - in contrast to ideal models or ex post facto rationalizations of development processes, participating actors and their intentions - seems unclear. The purpose was to get a deep and naturalistic account of the content of this kind of development process.

\subsection{Aims and research questions}

The aim of this study was to enhance the knowledge regarding actors and intentions in the development process of a mobile phone platform for self-management of hypertension. Two research questions have guided our analysis:

1) What actors appeared in the different phases of the development process?

2) What were the most prominent intentions or ideas actors brought up and tried to inscribe into the technology?

\section{Methods}

\subsection{Analytical framework and research approach}

ANT helps to conceptualize how different realities are experienced and enacted by different actors during the course of a process of, for example, technology development, including an appreciation of technologies as important [28]. ANT has informed the theoretical approach in this study, with particular emphasis on the following concepts: the process of translation, the actor (human/technical), and the concept of inscription [29-32]. ANT is a rich theory that first emerged in seminal texts by authors such as those cited above. More recently, Callon and Muniesa [33] and Czarniawska and Hernes [34] have made specialized contributions. This study applied certain basic concepts of ANT to a process in a field of praxis (the development of a mobile phone platform and associated technologies to manage hypertension). We argue that ANT studies often apply a number of concepts, increasing their theoretical complexity without gaining explanatory capacity. Our minimalistic or pragmatic [28] approach is the basis for the analysis of the actors and intentions in a development project. Authors [28] have 
recommended the application of ANT in health care research as useful in understanding the complexity of its organizational contexts, including the role of technology.

ANT has an equal, or symmetrical $[29,30]$, focus on humans and technologies. During processes of development like the one studied here, actors pursue their own interests, which they try to translate into social and technical arrangements. An inscription $[31,35]$ can be explained as a form of intention or anticipated behaviour that actors try to build into, for example, technical artefacts (e.g., the mobile phone platform) by means of such arrangements.

If we want to understand such processes, we must empirically follow the ways actors relate to each other and the intentions brought forward. Therefore, our research approach was a longitudinal, "real-time ethnography" method [27] of data collection and, subsequently, analysis. In this approach a researcher closely follows the events through observations, interviews and document analysis during the course of an innovation process of some kind. In this manner, it was possible to "follow the actors" closely and capture controversies and tensions as well as the general unfolding of the events they argue. A more general argument for this approach was the value of attaining a better notion of "practice".

\subsection{Material and participants}

The development process involved several types of patient, provider, expert and researcher (Table 1), knowledge and activities, as well as a multifaceted network of human actors and technologies. The technological actors were (Figure 1): (1) a mobile phone platform with selfreport questions about wellbeing, symptoms and treatment side effects, together with motivational messages about exercise and diet; (2) a device for measuring blood pressure; and (3) a Web-based platform for looking at patient-reported data via line graphs. 


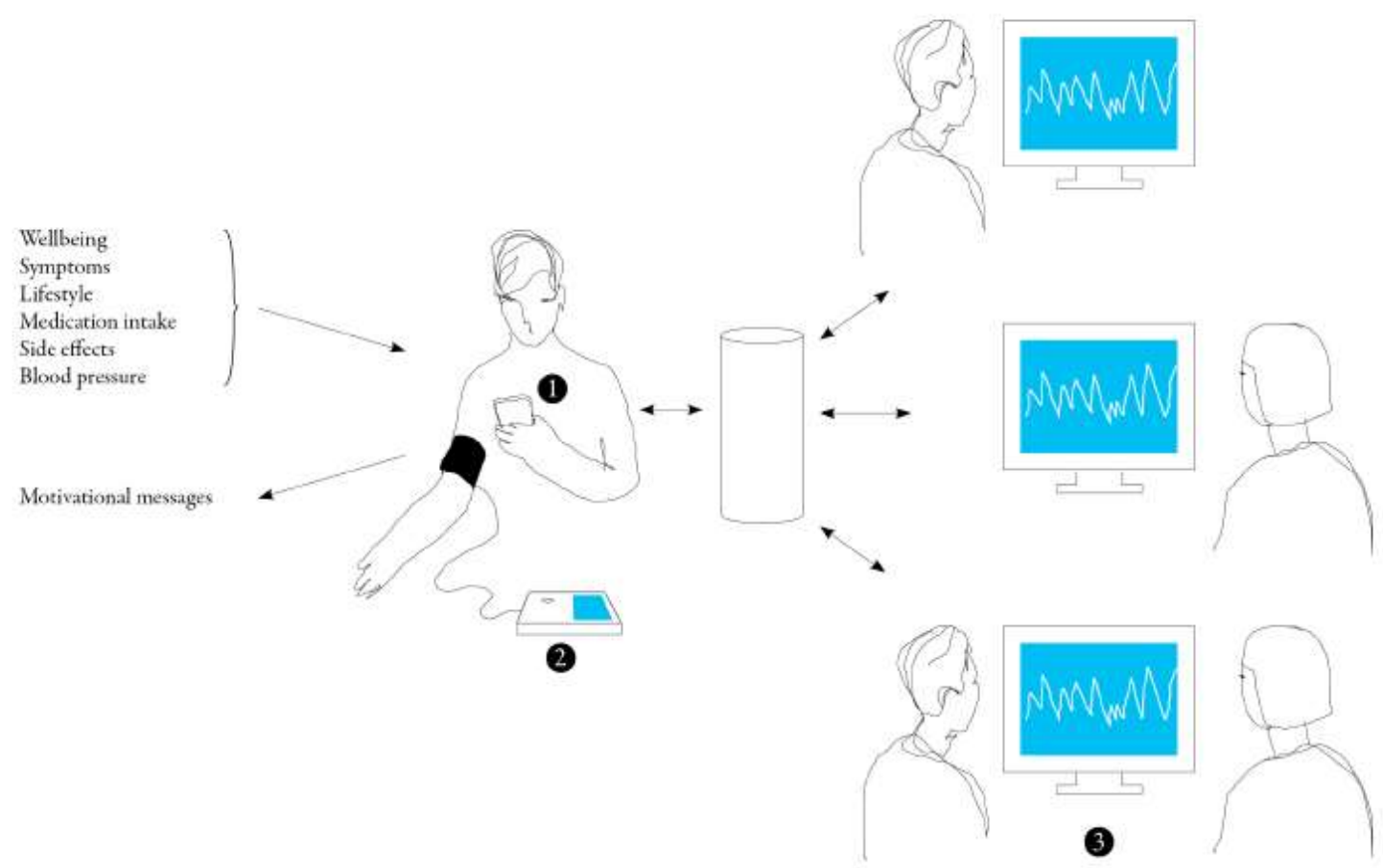

Figure 1. Overview of the self-management system. The system consists of:

1. Mobile phone platform for the self-report questions and the optional motivational messages.

2. Blood pressure device.

3. Web-based platform for real-time visualization of the patients' reported data via line graphs.

The study included a case involving the development of a mobile phone platform in which patients are to register data on blood pressure, symptoms, side effects and wellbeing. The research programme also included the other two types of technology (a device for measuring blood pressure and a Web-based platform for looking at graphs). These are not focused on in detail in this particular study except when they were mentioned during the design meetings. They were indeed used with the mobile phone platform, but this use took place after the development process.

The research programme entailed an intention to explore hypertensive patients' and health care providers' experiences and views regarding aspects of hypertension and hypertension 
treatment to be used in the development of a technology to support the management of hypertension. In this endeavour, focus group interviews were pursued (three with patients, two with providers, lasting 1.5-2 h) during April-August 2010. Fifteen patients were recruited, through an enquiry by their treating physician, from a primary health care centre and an outpatient medical clinic in Sweden. The inclusion criteria for patients were: $>30$ years of age and currently using drugs for hypertension. Twelve health care providers were recruited from the same units as the participating patients, and comprised equal numbers of physicians, nurses and pharmacists. The providers had to have experience of care for patients with hypertension [36].

Between November 2010 and August 2011, 10 design meetings (lasting 1.5-2.5 h) were held with participating researchers and technical experts. The participants in these meetings were two technical experts, one expertise nurse for hypertension and researchers from the following disciplines: health and care science $(n=4)$, education science $(n=2)$, psychology $(n=1)$, pharmacology, outcomes research $(n=1)$, medicine $(n=1)$ and theory of science $(n=1)$.

The focus group interviews, patient interviews and design meetings were recorded and transcribed. The questionnaire to be used in the self-report system was pre-pilot tested by two patients and pilot tested by 19 patients. These 21 patients, who met the criteria of currently being medically treated for hypertension, were asked by their treating provider to participate in the cognitive interviews [37]. Even though these rich sources of data were included, there is a limitation in that additional informal communication by e-mail and telephone was not included due to practical reasons.

(Table 1 approximately insert here) 


\subsection{Analysis}

The main author analysed the transcriptions of the focus groups and design meetings in detail, focusing on the involved actors (patients, providers, researchers and others) and their main intentions inscribed in the design of the technology to manage hypertension. The main author also analysed a summary of the transcribed patient interviews in this manner. The emergent development of the self-report questions was traced, resulting in a final version in August 2011. Cresswell et al. [28] acknowledged the problems involved with capturing the full picture of social reality. The description of the process and analysis was informed by the ANT framework, considering the basic concepts of actors and inscriptions. However, ANT can help researchers "zoom in" on particular aspects of how networks of human and technological actors are formed by closely "following the actors" in a very concrete manner in the development process [27]. Two specific questions guided our qualitative analysis: 1) What actors appeared in the different phases of the development process from the start to the finalization of the self-report questionnaire in the mobile phone platform? and 2) What were the most prominent intentions or ideas actors brought up and tried to inscribe into the technology? These questions mean that the ambition has been to provide a fair and representative account of the rich empirical material (3.1), as a foundation for further analysing the actors and intentions (3.2). In practice, the actors appearing were simple to capture. Regarding the intentions or ideas, the first author pursued a simple coding of the recurring themes at the highest relevant level ("discussion about the project aim", "discussion about the telephone questions" etcetera). The account produced in Section 3.1 served as a means to show the actual instances or content of these general themes. Admittedly, such an analysis can be made at different levels and in various levels of detail [28]. This qualitative study was based on a large amount of material, as described above. However, instead of a brief overview of processes and technologies as is often done in previous research (see Section 1.1), here we get a theoretically informed account of meetings and citations from 
participants (3.1), as well as a table presenting an overview (Table 2) as a foundation for analysis and result.

(Table2 approximately insert here)

\subsection{Ethics}

The research programme was approved by the Regional Ethics Board in Gothenburg, Sweden (study code 551-09). The patients and providers were given written and oral information regarding voluntary participation and explaining that their responses would be confidential. The experts and researchers were informed orally. The research programme was planned and conducted in accordance with the Declaration of Helsinki [38].

\section{Results}

\section{1 An account of the development process}

Hypertension is a serious condition that demands long-term medication. However, many patients feel that the antihypertensive medication itself causes trouble through side-effects, resulting in poor adherence to treatment [39]. With this as a background, Kjellgren et al. [40] conducted a study of patients with and without antihypertensive medication and found that both categories perceived symptoms. It was suggested that future studies focus on patients' more exact perceptions of treatment.

In an approved research application, Kjellgren and colleagues outlined a research programme entitled "Mastery and autonomy in medication with a mobile self-report system" [41]. It was argued that patients' perceptions of their illness and treatment may be the key to addressing the question of adherence. Tools for monitoring illness and treatment might therefore need to take these factors into account. The self-management system can be used for this purpose, for example by means of a mobile phone platform. In this endeavour, the research programme would design and evaluate such a technology to support hypertensive care [41]. 
The framework of the development process followed Phases 2 and 3 (Adjust Conceptual Framework \& Draft Instrument and Confirm Conceptual Framework) outlined by the Food and Drug Administration (FDA) in their Patient-Reported Outcomes Measures (PROM) guidance [42].

\subsubsection{Focus group interviews with patients}

The main researcher in Health Care Science and a technical expert working with the mobile phone platform participated in these interviews. The patients were generally satisfied with their current anti-hypertensive treatment, saying that the most important things were to feel safe, to have regular check-ups and to have good contact with a physician. When asked about their symptoms a few mentioned dizziness, heart palpitations, tiredness and headaches. Patients felt that the symptoms mentioned were good candidates for questions to ask via the mobile phone platform, and were explicitly requested to rank a list of suggested symptoms. These listed symptoms emanated from a population-based multicentre study of perceived symptoms amongst hypertensive patients [40].

The researcher also tried to elicit the patients' general feelings about the research programme idea by asking questions and explaining.

HCS1: What do you think about this way of following up on the medication?

PAT: I must say that I didn't fully understand it. I don't have a mobile now, but I used to. [...] I don't understand which situations you should communicate by phone in [...] If it's supposed to be of help to me personally?

HCS1: All patients are not as well-medicated as you are. [...] Many have to try out which medicine suits them best. And how you feel using these different types of medicine. [...] And then you can get questions in the mobile that you can answer. 
The technical expert demonstrated the functionality of the mobile phone platform, showing questions based on the Visual Analogue Scale (VAS) as well as motivational messages. When asked about their preferences concerning answering questions via the mobile phone, patients expressed a desire to answer rather seldom (once a month or once a week); but when the researcher explained that they would have to answer questions much more often than this, they expressed understanding.

\subsubsection{Focus group interviews with providers}

Also here, one main theme concerned symptoms of hypertension and hypertensive treatment. The general view among providers was that symptoms are rare, except for headache, stress and dizziness. As for side effects from treatment, these might also include headache and dizziness. It was considered important to follow up blood pressure measurement. Regarding adherence, the view was that many patients followed instructions but that there was great variation in this. Figures between 30 and 50\% non-adherence were mentioned.

The technician explained in detail about the different types of questions and answers that could be put into the mobile phone platform. When asked what should be put into the platform, the providers suggested topics such as tiredness, dizziness, headache and sleep.

Concerning the issue of the general idea of the research programme, the results were mixed: PROV1: There are great variations between our customers. Some will not be able to do this, but there are also those who will. PROV2: And I think that seeing 'how something is' can lead to changes. [But] it mustn't be too much, too messy.

\subsubsection{First version of the self-report questionnaire}

There were ten questions to be asked every day, beginning with How do you feel today? and What is your systolic and diastolic blood pressure today?, as well as two questions about Sleep and Stress; the VAS (Visual Analogue Scale) response scale was used. These questions were 
followed by two checklists about Symptoms and Side effects. There was also a question regarding Medication intake today, with the response alternatives Yes, Some of it, and No. Two motivational messages, chosen from a library of messages, were included in this sequence. There were also suggestions for messages about positive activities to be sent weekly, for instance whether the patient was Eating a cooked lunch, Eating fruit or Exercising.

\subsubsection{Design Meetings 1-6 with researchers}

Based on the first version of the self-report questionnaire, a small group (the main researcher in Health and Care Science and two others) discussed what would be put into the mobile phone platform (Meeting 1). The researchers discussed the inclusion of questions about stress, satisfaction with received treatment, blood pressure, physical activities and eating habits. Commenting on the two last issues, HCS2 said "It's very important to also include those positive, non-medical things [referring to the motivational messages]. We thought it would be fun to get them into the mobile so the whole thing won't be too heavy." Touching on the research programme's aim, another researcher (TS) asked "Is there an intention to be normative?" and the main researcher (HCS1) answered "Yes, there is an intention to change a behaviour."

At Meeting 2 the issue of the greater intention of the research programme was raised by a second technical expert. The main researcher described this as follows:

HCS1: And when you talk about high blood pressure today in the clinic you talk a lot about side effects like these [shows a picture of symptoms with and without antihypertensive medicine] and very little about the ones patients experience. [...] And you talk about risk factors. And therefore we have to bring this together with symptoms and signs in health care in a good way.

Concerning the questions to be included, the direct influence of patients was emphasized, among other things, in the FDA model used for the development. The difference in views 
between patients and providers expressed in the focus groups was mentioned by HCS1: "The patients perceive that you have high blood pressure and dizziness [...] while the providers perceive that very little of these symptoms are caused by the blood pressure". The response alternatives were also up for discussion, focusing on the use of the VAS or the Likert scale. The argument was that the VAS might look different in different mobile phones.

At Meeting 3, several sources of competence concerning how to design questions in the mobile phone platform were discussed: an edited research volume with chapters on the development of Patient-Reported Outcome Measures (PROM), a participating psychologist expert [PSY] and experts on the development of research instruments [PHA, HCS3]. Equally important would be gathering patient views in pilot interviews.

The discussion about the mobile phone questions continued, and included the issue of motivational messages and their greater motivation. HCS1: “We don't have to be locked in someone else's frame; it's we ourselves who decide what we think is good." The related issue of response scales was brought up, suggesting Likert instead of VAS.

At Meeting 4, the discussion about the best scale to use (VAS or Likert) resurfaced. This was connected partly to scientific reasons and partly to the mobile phone platform. It was argued that smart-phone technology made it easier to use different scales without risking the corruption of the question layout.

A further issue was a visiting expert nurse's presentation of the patients' measurement of their own blood pressure. The main researcher explained:

HCS1: And this is the main intention; that the patient becomes aware of the blood pressure they have - register it in the mobile phone and can look at it on the graphs. 
Interestingly, the issue of the larger aim of the project was brought up once again, by HCS1: "This is a design study, not a clinical controlled study. We want to bring forward knowledge from this design."

At Meeting 5 different aspects of the mobile phone questions were discussed, for example regarding the motivational messages but also the response scale. How different questions should be selected according to the patient's personal situation was also discussed: PSY: "So the expectation is that the physician takes the set of questions that he feels is applicable to this patient?". It was suggested that the mobile phone questions be more clearly related to the research programme and its aim:

PHA: So that's one hypothesis, then. [...] To build up this kind of model where you relate all the symptoms that are important and you also construct the conceptual framework of all the questions [...] so you don't miss anything.

At Meeting 6, the questions to be tested in the pilot study had been put in the mobile phones application in preparation for the pre-pilot interviews. When discussing the information leaflet to be shown to participating patients, the description of the project aim was brought up:

TS: The questions will be answered by patients in the mobile. [...] You say it's about improved adherence. But this research programme is also about patients gaining better control over their knowledge to become "Master and Autonomous."

The discussion about the motivational messages continued:

HCS2: It's about the 'to be or not to be' of the motivational messages. But at this point we say they should be included. We want that, and I've discussed it with [TECH1] quite a lot. We've made a little repertoire of messages to be tried out. It's difficult. A motivational message might work for one person but not for another. 


\subsubsection{Pre-pilot cognitive interviews}

At two pre-pilot interviews, patients were given the opportunity to test the different questions using a borrowed mobile phone, as well as to measure and register their own blood pressure. Afterwards a detailed interview was held. Some questions and motivational messages ("Have you done any yoga, read, cooked lunch?") were characterized as irrelevant by one of the patients.

\subsubsection{Design Meeting 7 with researchers}

During this meeting, the two pre-pilot interviews with patients were referred to. One issue was the importance of communicating the aim of the research programme. It was argued that the issue of the graphs with patient data, accessed via the Web, had disappeared in the interviews.

The views of the two interviewed patients about the motivational messages (one in favour, one more vague) were referred to. The risk that these messages would affect the results of the study was also brought up, but it was suggested that they could be omitted or tailored to the individual patient. It was determined that the main researchers and one technician should be consulted about their inclusion.

\subsubsection{Pilot cognitive interviews}

Pilot interviews were held with 19 patients, during which the patients had the opportunity to test the questions. A first question about wellbeing was interpreted as either more general or closely related to hypertension. Some of the response alternatives were discussed, for example "partly" taking one's medicine and a "neither-nor" alternative. Some questions about side effects of medication were regarded as irrelevant to certain interviewees. The wording of questions and answers about "physical activity" was questioned. Lastly, patients' views about motivational messages were rather positive. 


\subsubsection{Design Meetings 8-10 with researchers}

At Meeting 8, the pilot interviews with patients were further discussed. The rationale behind these interviews was described as focusing on the emergent learning about patients' views on questions.

The motivational messages were discussed and the patients' responses were referred to: ED2: "Yes, it's a bit mixed. I can say that it was 50/50 between those who thought it was good [and those who didn't]." The motivational messages were connected to the aim of the research programme:

HCS3: Yes, it's when you measure the blood pressure and then maybe you should get a message that 'Yes, you should go and rest'. [...] and maybe go home and think, and contact health care.

HCS1: But the "Master \& Autonomy" research programme is very much about this; how autonomous is the patient? [...] We're getting a tool that we have to handle in relation to these issues.

At Meeting 9, the research programme aim was brought up by researchers:

MED: “When listening to you, [I wonder] what's really the purpose of this? And now it's more about the adherence and following the patients [...] and then we have the measure to count the number of tablets and things like that." This was answered in the following manner: HCS1: "The purpose of the whole research programme is to improve adherence. It's about autonomy and mastery in the management of hypertension."

At Meeting 10, the influence of providers and patients on questions was brought up: HCS2: We rely on the things patients tell us but we also include [...] several years of experience from hypertensive patients. 
HCS1: I thought about participatory design. [...] And I think it's important to begin based on that, because otherwise we have to work for it to be accepted in clinical praxis. That the professions have been allowed to contribute their views.

TS: Yes, the professions should be allowed to take part, but who has the right to decide?

A new issue was the design of the forthcoming three-month study of patients' use of the mobile phone and their Web-based access to their registered data through graphs. An introductory meeting between the physician, the nurse and the patient would be necessary but must be kept simple to enhance access, it was argued. In line with this, the issue of motivational messages was brought up: HCS1: "Concerning the issue of motivational messages, I read an article during the summer that contained very good [experiences]."

\subsubsection{Final self-report questionnaire}

As an important part of the mobile phone platform (Figure 1) there were 12 questions to be asked every day, beginning with How do you feel today? and followed by questions about Antihypertensive medicine, Tiredness, Dizziness, Headache, Heart palpitations, Restlessness, Sleep, Physical activity and Stress; a Likert response scale was used. The two questions What is your systolic blood pressure today? and What is your diastolic blood pressure today? were placed last. There were some questions about side effects of medication to be submitted weekly (Swollen ankles, Dry mouth, Dry cough and Frequent micturition). Lastly, there was also a library of 11 motivational messages.

\subsection{An analysis of the development process}

\subsubsection{Participating actors}

Our account shows that hypertensive patients, providers, experts and researchers (Table 1) took part in the development process. The patients participated in focus groups aiming to get input on the design of appropriate questions. They also took part in pre-pilot and pilot interviews, 
commenting on the appropriateness of the proposed questions, the answer models, the motivational text message and the ease of answering from a technological point of view. The providers participated in focus groups discussing virtually the same issues, but expressed scepticism regarding the existence of symptoms and the use of mobile phones.

In contrast, researchers from various disciplines took part in the whole process through focus group interviews, pilot interviews and design meetings. The researchers were made up of a core group within Health and Care Science and Theory of Science. An outer circle of researchers representing pedagogy, psychology, medicine and pharmacology also took part on certain limited occasions. A further group was comprised of experts on the mobile phone platform. Their focus was on presenting the platform as well as helping in the development of questions.

The composition of these actors relates to the issue of how both lay and scientific knowledge $[3,4]$ are part of the processes in which decision support for patients is developed. It can be concluded that development processes might involve patients, providers and researchers as well as technicians, thus being a part of PD practices [23]. The actors, with their respective types of lay, scientific and technological knowledge, can be actively involved as a rationale behind the process organization. In our study, PD was part of the argument behind the research programme's emphasis on the necessity to capture patients' own beliefs [41], the applied FDA model for development (Meeting 2) and the intention to anchor the technology among providers so it will be accepted in clinical praxis (Meeting 10). It might also be part of a more general understanding of how to organize these kinds of development processes [19, 21]. Despite this presence of PD practices we can also see how, with the main exception of researchers in Health Care Science, the patients might be active in comparatively distinct and limited parts of the development process (focus group discussions, patient interviews). The participation of patients 
might thus be limited in time as well as conceptually, even though patients' perceptions are an important aspect of the motivation for the study.

\subsubsection{Intentions}

Interestingly, the intentions the actors brought up and wanted to inscribe into technology (3.1) did not vary much during the course of the process (Table 2). In the focus groups there was a dialogue between researchers, technicians and patients about the appropriate questions to be put into the mobile phone platform and the idea of hypertensive patients using mobile phones (Focus groups, Pilot interviews, Meetings 1, 5, 7). A repertoire of questions to be put into the platform introduced at the first design meeting was changed regarding details in wording. The response scale first suggested was the VAS, whereas Likert was the final choice (Meetings 2, $3,4,5)$. The question about the result of patients measuring their blood pressure was positioned at the beginning in the first version, but at the end in the last one, to avoid affecting the answers to the questions.

The motivational messages and their associated inscribed behaviour were more controversial. The positive experiences of such messages in previous research were referred to (Meetings 1, 10), whereas their origin, problems involved with selecting appropriate messages, and their actual effects were more open points (Meetings 3, 5, 6, 7, 8).

The issue of the aim of the research programme representing the most important inscription of aspired behaviour also reappeared. The general importance of communicating its aim (Meeting 7), the aspect of connecting symptoms with signs (Meeting 2) and the fact that the research programme was a design study testing the use of the mobile phone platforms (Meeting 4) were emphasized. However, there was repeated discussion about the mastery and learning dimension versus measuring adherence (Meetings 5, 6, 8).

Lastly, the technology in the form of Web support for showing graphs with patientregistered data was part of the discussion, for example the extent to which patients would have 
access to the data (Meeting 4), and physicians' and nurses' access as well as the actual use of the data in the forthcoming clinical study (Meeting 10).

\section{Discussion}

In the development process there was deliberation regarding the mobile phone questions with regard to the features of the mobile phone platform allowing for certain lengths of questions and standards of answering, but also the scientific aim of designing valid questions. There was also deliberation regarding the motivational messages with regard to the features of the platform offering this opportunity, the scientific aim of designing valid questions and the aim of designing a clear cause-and-effect relationship between the questions. Furthermore, there was deliberation regarding the fact that the features of the mobile phone platform offered the opportunity to answer questions easily. However, this was deeply dependent on the whole constellation of involved technologies, and the scientific need to make the entire aim of the research programme clear and implement it. To conclude, the actors' discussion of intentions might thus focus on a few concrete issues at the same time as it contains tensions related to the affordances of the motivational technology [43] as described. Navigability, interactivity and customization are examples of affordances of such technology that are explicitly said to have a positive effect on users' motivation [43]. In our study, the affordances in the form of the mobile phone platform's capacity to support easy questioning and answering as well motivational messages offered options for design and use. At the same time, they encompassed limitations of design and use, as well as affected the scientific and causal model that was constructed.

The results thus showed that not only the patients, researchers and technology experts but also the technologies themselves might be important as viable affecting the discourse and the emergent definition of central intentions related to, for example, the research programme aim 
and the mobile phone questions (Table 2). In fact, in a subsequent three-month user evaluation of the mobile phone platform, the order of the questions has once again been changed due to the affordances of the technology, with the measurement of blood pressure having to be done first instead of last. The role of technology as an actor is not a conclusion based on technological determinism or ex post facto rationalization. Instead, it is based on the concrete experiences of following the actors in an innovation process [27] and their discourse related to the design. We argue that this manner of studying innovation processes helps uncover otherwise hard to detect controversies as well as choices made by situated actors. The role of technology as a fully fledged actor affecting important aspects in projects developing decision support for chronic patients, as in our case here, might be seen as the most important result of this.

Against the background of our analysis, it can also be concluded that the greater result of the development process of a technology for managing hypertension expressing the intentions of participating actors can be summarized as follows:

1) Questions and answers in a mobile phone platform. In the case studied here, these were developed against the background of previous research and focus groups fit for inclusion in clinical studies [19]. This was a result of both patients' (lay) and researchers' (scientific) knowledge and input.

2) A more indirectly emerging causal model made up of issues of interest to be measured in a scientific project. This discussion had only begun during the above-discussed period of the design meetings in our study.

3) A first step in a researcher-initiated attempt to support learning and offer the capacity to act through a mobile phone platform and accompanying technological devices.

4) A rather advanced "treatment model" aimed at supporting what was characterized as "Mastery and autonomy in medication" [41] in the form of questions on the mobile phone platform in conjunction with the capacities of other technologies. This model includes the issues 
of interest that are part of the mobile phone questions, gradually making up a causal scientific model. Added to this is the capacity to enhance comparisons of reported data related to these issues and the generation of new patient or lay knowledge ("model for learning") through this Web-based support showing graphs (Figure 1). No less important are the motivational messages that can be selected by providers and patients to stimulate changed behaviour. We thus see how, in different ways, all these forms of results support a general ambition to attain a change of behaviour through patients using the technology and subsequently measuring the actual effect by means of implementing the scientific model.

Further, a finding in studies concerned with the relationship between lay and scientific knowledge like ours, relying on a co-production model through the use of PD, is that universal scientific knowledge can be challenged or modified by lay knowledge [44]. This is because scientific recommendations are of a contextual aggregated character. This means that such recommendations are not always appropriate, and are therefore not followed, in the multifaceted reality of everyday life. From an education model, this is often interpreted as a lack of adherence by an individual patient. An important and very difficult task in PD would therefore be the issue of how to generalize or aggregate particularity as expressed by the layperson. In our study as well as in others, it is investigated how patients themselves, via focus groups, have been encouraged to reach a general level rather than a personal, individual one. On the other hand, in our case, the technology produces "individual" graphs whereby this individuality is conditioned or controlled as part of the scientific interest. Another example of this is the patients' suggestion that, based on their lay experience, it would be appropriate to answer the telephone questions monthly or weekly. From a scientific or research point of view, this is not adequate.

To conclude, treatment models involving a self-management system might express a tension between lay and scientific knowledge even if patients are given an important role in the 
development process. In the case studied here, one could argue that this tension is also represented in the greater intention to enhance patients' mastery and autonomy while simultaneously increasing adherence. We indeed have a paradox here, since these two intentions are seemingly contradictory. Instead, we argue, their relationship is close when considering the actual goal, which in the particular case studied here was to ensure wellcontrolled blood pressure.

It is important to acknowledge that patients' actual capacity to act that is attained in projects developing systems for managing chronic illness will depend on how the constructed "treatment model" is to be further developed after the clinical testing. The actual results, of course, will also partially depend on the appropriation of technology in institutionalized use in patients' own life situations [45]. The symmetrical ambition of our applied theoretical framework [29, 30] offers an explanation of our joint result of actors and intentions: both humans and technologies play important roles, as discussed above.

Lehoux et al. [22] showed the nuances of participating actors' knowledge and roles in creating a "medical instrument" or object. In contrast, here, by following a process of development studied using "real-time ethnography" methods, we conclude that the appearing actors and their knowledge are not only multifaceted but also the result of the development as described. Concerning previous studies on mobile phone platforms in the management of chronic illness in general, and hypertension in particular, we have contributed by offering an in-depth review of actors and intentions. This complements previous research [13-16] with a focus on technical design, distant descriptions of development processes, and outcomes.

There are limitations to this study: the results are based on a single case study. However, they show an account of actors and intentions, which hopefully mediates the naturalistic character of the development process. Further studies might involve a comparative case approach involving two to four similar cases of development. An interesting issue would also 
be a study of real use and users [28], evaluating the long-term effects on patient autonomy and mastery.

\section{Conclusions}

Our study showed that laypersons, experts and scientific actors as well as technology itself influence development processes of support for patients in managing hypertension. The intentions were inscribed into technology design as well as models of learning and treatment. This illustrated the multifacetedness of the results of such projects. During the course of the process, tensions emerged in the translation from lay knowledge, generated by PD, to scientific knowledge in the later phases. We have also detected the apparent "paradox" of introducing a self-management system for hypertensive patients and the intention to increase adherence.

\section{Acknowledgements}

We are indebted to the patients, providers, experts and researchers for their contributions to this research.

\section{Competing interests}

The authors declare that they have no competing interests. The research reported here has been financed by and conducted within the University of Gothenburg LETStudio, in collaboration with the Gothenburg Centre for Person-Centred Care (GPCC) in Sweden. The LETStudio is a strategic initiative for promoting interdisciplinary research within the Learning Sciences at the University of Gothenburg. It addresses issues of knowledge, learning, communication and expertise in contemporary society. The GPCC is funded by the Swedish Government's grant for Strategic Research Areas, Care Sciences [Application to Swedish Research Council nr 2009-1088], and co-funded by the University of Gothenburg, Sweden. 


\section{References}

[1] Blake H. Innovation in practice: mobile phone technology in patient care. Br J Community Nurs 2008;13:160, 162-165.

[2] Blake H. Mobile phone technology in chronic disease management. Nurs Stand 2008;23:43-46.

[3] Brown MB. Science in democracy : expertise, institutions, and representation. Cambridge, Mass.: MIT Press; 2009.

[4] Mol A. The logic of care: health and the problem of patient choice. Abingdon, Oxon: Routledge; 2008.

[5] Lim SS, Vos T, Flaxman AD, et al. A comparative risk assessment of burden of disease and injury attributable to 67 risk factors and risk factor clusters in 21 regions, 1990-2010: a systematic analysis for the Global Burden of Disease Study 2010. Lancet 2012;380(9859):2224-2260.

[6] Lozano R, Naghavi M, Foreman K, et al. Global and regional mortality from 235 causes of death for 20 age groups in 1990 and 2010: a systematic analysis for the Global Burden of Disease Study 2010. Lancet 2012;380(9859):2095-2128.

[7] Krishna S, Boren SA. Diabetes self-management care via cell phone: a systematic review. J Diabetes Sci Technol 2008;2:509-517.

[8] Krishna S, Boren SA, Balas EA. Healthcare via cell phones: a systematic review. Telemed J E Health 2009; 15:231-240.

[9] Free C, Knight R, Robertson S, Whittaker R, Edwards P, Zhou W, et al. Smoking cessation support delivered via mobile phone text messaging (txt2stop): a single-blind, randomised trial. Lancet 2011;378:49-55.

[10] Vodopivec-Jamsek V, de Jongh T, Gurol-Urganci I, Atun R, Car J. Mobile phone messaging for preventive health care. Cochrane Database Syst Rev 2012;12:CD007457. 
[11] Li LC, Townsend AF, Badley EM. Self-management interventions in the digital age: New approaches to support people with rheumatologic conditions. Best Pract Res Clin Rheumatol 2012;26(3):321-333.

[12] de Jongh T, Gurol-Urganci I, Vodopivec-Jamsek V, Car J, Atun R. Mobile phone messaging for facilitating self-management of long-term illnesses. Cochrane Database Syst Rev 2012;12:CD007459.

[13] Rodrigues JJ, Lopes IM, Silva BM, Torre Ide L. A new mobile ubiquitous computing application to control obesity: SapoFit. Inform Health Soc Care 2013;38:37-53.

[14] Whittaker R, Merry S, Dorey E, Maddison R. A Development and Evaluation Process for mHealth Interventions: Examples From New Zealand. J Health Commun 2012;17(sup1):1121.

[15] Logan AG, McIsaac WJ, Tisler A, Irvine MJ, Saunders A, Dunai A, et al. Mobile phonebased remote patient monitoring system for management of hypertension in diabetic patients. Am J Hypertens 2007;20:942-948.

[16] Logan AG. Transforming hypertension management using mobile health technology for telemonitoring and self-care support. Can J Cardiol 2013;29(5):579-585.

[17] Elwyn G, Kreuwel I, Durand MA, Sivell S, Joseph-Williams N, Evans R, et al. How to develop web-based decision support interventions for patients: a process map. Patient Educ Couns 2011;82:260-265.

[18] Ekberg J, Ericson L, Timpka T, Eriksson H, Nordfeldt S, Hanberger L, et al. Web 2.0 Systems Supporting Childhood Chronic Disease Management: Design Guidelines Based on Information Behaviour and Social Learning Theories J Med Syst 2010;34:107-117.

[19] Berry DL, Halpenny B, Wolpin S, Davison BJ, Ellis WJ, Lober WB, et al. Development and Evaluation of the Personal Patient Profile-Prostate (P3P), a Web-Based Decision Support 
System for Men Newly Diagnosed With Localized Prostate Cancer. J Med Internet Res 2010;12:109-121.

[20] Berg M, Adolfsson A-S, Ranerup A, Sparud-Lundin C. Person-centered web support to women with type 1 diabetes in pregnancy and early motherhood - the development process. Diabetes Technol Ther 2013; 15(1): DOI: 10.1089/dia.2012.0217

[21] Pasternack I, Saalasti-Koskinen U, Mäkelä M. Decision aid for women considering breast cancer screening. Int J Technol Assess Health Care 2011;27:357-362.

[22] Lehoux P, Hivon M, Williams-Jones B, Urbach D. The worlds and modalities of engagement of design participants: A qualitative case study of three medical innovations. Design Studies 2011;32:313-332.

[23] Spinuzzi C. The methodology of participatory design. Tech Commun 2005;52:163-174. [24] Høstgaard AM, Bertelsen P, Nøhr C. Methods to identify, study and understand end-user participation in HIT development. BMC Med Inform Decis Mak 2011;11:57.

[25] Shah SGS, Robinson I. Benefits of and barriers to involving users in medical device technology development and evaluation. Int J Technol Assess Health Care 2007;23:131-137. [26] Torsi S, Nasr N, Wright PC, Mawson SJ, Mountain GA. User-centered design for supporting the self-management of chronic illnesses: an interdisciplinary approach. Proceedings of the 2nd International Conference on Pervasive Technologies Related to Assistive Environments. Corfu, Greece2009. p. 1-4.

[27] Hoholm T, Araujo L. Studying innovation processes in real-time: The promises and challenges of ethnography. Ind Market Manag 2011;40:933-939.

[28] Cresswell KM, Worth A, Sheikh A. Actor-Network Theory and its role in understanding the implementation of information technology developments in healthcare. BMC Med Inform Decis Mak 2010;10:67. 
[29] Callon M. Some elements of a sociology of translation: Domestication of the scallops and the fisherman of St Brieuc Bay. In: Power, action, and belief: a new sociology of knowledge. London: Edited by Law J. Routledge \& Kegan Paul; 1986. p. 196-233.

[30] Latour B. Where are the missing masses? The sociology of a few mundane artifacts In: Bijker W, Law J, editors. In Shaping technology/building society : studies in sociotechnical change. Cambridge, Mass.: MIT Press; 1992. p. 225-58.

[31] Akrich M. The de-scription of technical objects. In: Bijker WE, Law J, editors. Shaping technology/building society : studies in sociotechnical change. Cambridge, Mass.: MIT Press; 1992. p. 205-24.

[32] Latour B. Science in action: how to follow scientists and engineers through society. Milton Keynes: Open University Press; 1987.

[33] Callon M, Muniesa F. Economic markets as calculative collective devices. Organ Stud 2005;26(8):1229-1250.

[34] Czarniawska B, Hernes T. Actor-network theory and organizing. Malmö: Liber; 2005. [35] Callon M. Techno-economic networks and irreversibility. In: Law J, editor. A sociology of monsters : essays on power, technology and domination. London: Routledge; 1991. p. 13261.

[36] Bengtsson U, Kasperowski D, Ring L, Kjellgren, K. Developing an interactive mobile phone self-report system for self-management of hypertension. Part 1: Patient and professional perspectives. Blood Press. In press: 2014 [37] Beatty PC, Willis GB. Research Synthesis: The Practice of Cognitive Interviewing. Public Opin Q 2007;71:287-311.

[38] World Medical Association. Declaration of Helsinki, Ethical Principles for Medical Research Involving Human Subjects. 2008. Available from: http://www.wma.net/en/30publications/10policies/b3/index.html 
[39] Sabate E, (ED). Adherence to long-term therapies. Evidence for action. In: World Health Organization, editor. Geneva, Switzerland 2003. Available from: http://www.who.int/chp/knowledge/publications/adherence_report/en/index.html [40] Kjellgren KI, Ahlner J, Dahlof B, Gill H, Hedner T, Saljo R. Perceived symptoms amongst hypertensive patients in routine clinical practice- a population-based study. J Intern Med 1998;244:325-332.

[41] Ranerup A, Hallberg I, Bengtsson U, Kjellgren K. Mastery and autonomy in medication with a mobile self-report system: A project in action. Persuasive 2012 Adjunct Proceedings. Linköping, Sweden, June 6-8, 2012. p. 53-56.

[42] US Department of Health and Human Services Food and Drug Administration. Guidance for Industry: Patient-Reported Outcome Measures: Use in Medical Product Development to Support Labeling Claims 2009. Available from: http://www.ispor.org/workpaper/FDA\%20PRO\%20Guidance.pdf [43] Sundar SS, Bellur S, Jia H. Motivational Technologies: A Theoretical Framework for Designing Preventive Health Applications. In: Bang M, Ragnemalm E, editors. Persuasive Technology Design for Health and Safety: Springer Berlin Heidelberg; 2012. p. 112-122. [44] Horst M. Public expectations of gene therapy: Scientific futures and their performative effects on scientific citizenship. Sci Technol Human Values 2007;32:150-171.

[45] Storni C. Multiple Forms of Appropriation in Self-Monitoring Technology: Reflections on the Role of Evaluation in Future Self-Care. Int J Hum Comput Interact 2010;26:537-561. 


\section{Legends}

Table 1. Events and participating actors in the development process

Table 2. Overview of the development process

Figure 1. Overview of the self-management system. The system consists of:

4. Mobile phone platform for the self-report questions and the optional motivational messages.

5. Blood pressure device.

6. Web-based platform for real-time visualization of the patients' reported data via line graphs. 
Table 1. Events and participating actors in the development process.

\begin{tabular}{ll}
\hline Event type & Participators $^{1}$ \\
\hline Patient focus group interviews & HCS 1, TECH1, PAT \\
Provider focus group interviews & HCS1, TECH1, PROV \\
Design Meeting 1 & HCS1, HCS2, TS \\
Design Meeting 2 & HCS1, TS, TECH2, PSY, MED, PHA \\
Design Meeting 3 & HCS1, HCS2, TS \\
Design Meeting 4 & HCS1, HCS2, TS, TECH1, HCS3, NUR \\
Design Meeting 5 & HCS1, HCS2, TS, PSY, PHA, ED1 \\
Design Meeting 6 & HCS1, HCS2, TS, ED2 \\
Pre-pilot cognitive interviews & HCS2, ED2, PAT \\
Design Meeting 7 & HCS2, TS, ED2 \\
Pilot cognitive interviews & HCS2, ED2, PAT \\
Design Meeting 8 & HCS1, HCS3, TS, ED2 \\
Design Meeting 9 & HCS1, HCS2, HCS3, TS, PSY, PHA, MED, ED2 \\
Design Meeting 10 & HCS1, HCS2, HCS4, TS, ED1, ED2 \\
\hline 19bbreviations concerning participating actors (patients, providers, researchers and experts): PAT= Patients, \\
PROV= Providers, HCS= Health and Care Science, TS= Theory of Science, TECH= Expertise on mobile \\
telephone technology for patients, PSY= Psychology, ED= Education Research, NUR= Expertise nurse for \\
hypertension, PHA= Pharmacology, MED=Medicine
\end{tabular}


Table 2. Overview of the development process.

\begin{tabular}{|c|c|c|c|c|c|c|c|c|c|c|c|c|c|c|}
\hline \multicolumn{9}{|c|}{ Adjust Conceptual Framework $^{b}$} & \multicolumn{6}{|c|}{ Confirm Conceptual Framework $^{b}$} \\
\hline & \multicolumn{2}{|c|}{ Focus groups } & \multicolumn{6}{|c|}{ Design Meetings } & \multirow{2}{*}{$\begin{array}{l}\text { Pre-pilot } \\
\text { interviews }\end{array}$} & \multirow{2}{*}{\begin{tabular}{|l}
$\begin{array}{l}\text { Design } \\
\text { Meeting }\end{array}$ \\
7
\end{tabular}} & \multirow{2}{*}{$\begin{array}{l}\text { Pilot } \\
\text { Interviews } \\
\text { Patients } \\
(n=19)\end{array}$} & \multicolumn{3}{|c|}{$\begin{array}{l}\text { Design } \\
\text { Meetings }\end{array}$} \\
\hline & $\begin{array}{l}\text { Patients } \\
(\mathrm{n}=3)\end{array}$ & $\begin{array}{l}\text { Providers } \\
(\mathrm{n}=2)\end{array}$ & 1 & 2 & 3 & 4 & 5 & 6 & & & & 8 & 9 & 10 \\
\hline Intentions $^{\mathrm{a}}$ & & & & & & & & & & & & & & \\
\hline$-\mathrm{Aim}$ & $\mathrm{X}$ & $\mathrm{X}$ & $\mathrm{X}$ & $\mathrm{X}$ & & $\mathrm{X}$ & $\mathrm{X}$ & $\mathrm{X}$ & & $\mathrm{X}$ & & $\mathrm{X}$ & $\mathrm{X}$ & \\
\hline -Draft of questions & $\mathrm{X}$ & $\mathrm{X}$ & $\mathrm{X}$ & & & & $\mathrm{X}$ & & $\mathrm{X}$ & $\mathrm{X}$ & $\mathrm{X}$ & & & \\
\hline -Response scale & $\mathrm{X}$ & $\mathrm{X}$ & & $\mathrm{X}$ & $\mathrm{X}$ & $\mathrm{X}$ & $\mathrm{X}$ & & $\mathrm{X}$ & & $\mathrm{X}$ & & & \\
\hline -Motivational messages & $\mathrm{X}$ & & $\mathrm{X}$ & & $\mathrm{X}$ & & $\mathrm{X}$ & $\mathrm{X}$ & $\mathrm{X}$ & $\mathrm{X}$ & $\mathrm{X}$ & $\mathrm{X}$ & & $\mathrm{X}$ \\
\hline -Graphs access to the data & & & & & & $\mathrm{X}$ & & & & $\mathrm{X}$ & & & & $\mathrm{X}$ \\
\hline
\end{tabular}

aThe main intentions of the actors in the qualitative process and their connection to different parts of the development process are marked with X.

${ }^{\mathrm{b}}$ The table shows all phases of the development process and the overarching levels according to the FDA model [29]. 